\title{
TO ASSESS THE QUALITY OF LIFE OF PACLITAXEL BASED DOSE DENSE AND CONVENTIONAL NEOADJUVANT CHEMOTHERAPY IN LOCALLY ADVANCED FEMALE BREAST CANCER PATIENTS
}

\author{
Nonam Chellappan ${ }^{1}$
}

${ }_{1}^{1}$ Assistant Professor, Department of Radiotherapy, Government T. D. Medical College, Alappuzha, Kerala, India.

\section{ABSTRACT}

\section{BACKGROUND}

Breast cancer has become one of the most common cancers in women all over the world. It is a heterogeneous disease. Locally advanced breast cancer most commonly is diagnosed after a palpable mass is detected within the breast.

The aim of this study is to assess the quality of life of paclitaxel-based dose dense and conventional neoadjuvant chemotherapy in locally advanced female breast cancer patients.

\section{MATERIALS AND METHODS}

This observational study design was done between January 2011 and November 2012. A total of hundred locally advanced female breast cancer patients randomly selected from Department of Oncology, Government Medical College, Thiruvananthapuram. Fifty patients received paclitaxel $200 \mathrm{mg} / \mathrm{m}^{2}$ and doxorubicin $50 \mathrm{mg} / \mathrm{m}^{2}$ (4 course) every three weeks and other fifty patients received paclitaxel $80 \mathrm{mg} / \mathrm{m}^{2}$ weekly ( 10 course) along with doxorubicin $50 \mathrm{mg} / \mathrm{m}^{2}$ ( 4 course) every three weeks. Chemotherapy-induced toxicities and the quality of life of patients evaluated weekly (Total 10 weeks) by using Karnofsky Performance Status, Hamilton Depression scale, FACT-B (Functional Assessment of Cancer Therapy of Breast) and FACT-Taxane. Patients underwent modified radical mastectomy after the $4^{\text {th }}$ week of chemotherapy and received adjuvant chemotherapy (Fluorouracil $500 \mathrm{mg} / \mathrm{m}^{2}$, doxorubicin $50 \mathrm{mg} / \mathrm{m}^{2}$, cyclophosphamide $500 \mathrm{mg} / \mathrm{m}^{2}$ four course), external beam radiotherapy (dose of $50 \mathrm{~Gy}$ in 25 fractions using co-radioactive isotope) and hormone therapy for those who have receptor status positive.

\section{RESULTS}

Weekly patients had more problems regarding physical and social well-being, significantly less functional and emotional wellbeing, significantly more additional chemotherapy related problems and Taxane toxicity than three weekly patients. Based on Karnofsky Performance Status, three weekly patients had better performance status. Hamilton Depression Scale shows more depression in weekly patients.

\section{CONCLUSION}

This study shows that the quality of life during neoadjuvant chemotherapy in locally advanced female breast cancer patients was better in three weekly arm. Patients in three weekly arm have significantly more functional and emotional well-being. Patients in weekly arm had more depression which may be due to the physical problem, poor performance status, frequent hospital visits and change in life pattern.

\section{KEY WORDS}

Quality of Life, Neoadjuvant Chemotherapy, Locally Advanced.

HOW TO CITE THIS ARTICLE: Chellappan N. To assess the quality of life of paclitaxel based dose dense and conventional neoadjuvant chemotherapy in locally advanced female breast cancer patients. J. Evolution Med. Dent. Sci. 2018;7(31):3496-3501, DOI: $10.14260 /$ jemds/2018/787

\section{BACKGROUND}

Breast cancer has become one of the most common cancers in women all over the world. It is a heterogeneous disease. Locally advanced breast cancer is a relatively non-specific term referring to bulky invasive tumours that may have varying degrees of breast skin and/or chest wall involvement or cases with matted axillary and/or supraclavicular nodal disease without distant spread. ${ }^{1}$ Locally advanced breast cancer most commonly is diagnosed after a palpable mass is detected within the breast.

'Financial or Other Competing Interest': None.

Submission 12-06-2018, Peer Review 14-07-2018,

Acceptance 20-07-2018, Published 30-07-2018.

Corresponding Author:

Dr. Nonam Chellappan,

Assistant Professor,

Department of Radiotherapy,

Government T.D. Medical College,

Alappuzha, Kerala, India.

E-mail: achusnith605@gmail.com

DOI: $10.14260 /$ jemds $/ 2018 / 787$
Patients with these Cancers include those with-

1. Operable disease at presentation (Stage T3N1),

2. Inoperable disease at presentation (Stage T4 and/or N2-3),

3. Inflammatory breast cancer (Stage T4d No-3).

Patients who present with locally advanced breast cancer are at risk for both distant spread and local-regional disease recurrence. Optimal treatment of locally advanced breast cancer requires a multidisciplinary approach that incorporates diagnostic imaging, chemotherapy, surgery, radiation and if indicated biological and hormonal therapies. ${ }^{2}$ Neoadjuvant chemotherapy implying that the patients will receive chemotherapy before the complete surgical removal of the carcinoma. Neoadjuvant chemotherapy is the recent standard of care for the treatment of locally advanced breast cancer, ${ }^{1}$ which give pathologic complete response. ${ }^{3}$

Anthracycline and taxane bases neoadjuvant chemotherapy are appropriate for women with locally advanced breast cancer. ${ }^{4,5}$ The vast majority of patients will have clinical response to neoadjuvant chemotherapy and 
roughly $15 \%$ to $25 \%$ will experience a complete pathological response. ${ }^{2}$ The addition of paclitaxel to anthracycline-based therapy appears to improve long-term disease outcomes for women with locally advanced breast cancer and inflammatory breast cancer. ${ }^{2}$ Paclitaxel producing a number of adverse effects include severe allergic reactions, cardiovascular problems, infections (febrile neutropenia) developing from white blood cell deficiencies, hair loss, joint and muscle pain, low red cell count, peripheral neuropathy, mouth or lip sore and stomach upset or diarrhoea. ${ }^{5}$ Anthracycline causes side effects that include bone marrow suppression, immune system suppression, liver toxicity, skin disorders, central nervous system disorders and genitourinary and gastrointestinal complications such as inflammation of the lining of the mouth and intestines. ${ }^{6}$

A diagnosis of breast cancer is one of the most devastating things a woman can hear. ${ }^{7}$ This cancer is a very traumatic experience for patients, facing the possibility of death, changes in the body image by loss of weight, appetite and metastatic symptoms, fear of treatments like surgery, radiotherapy, chemotherapy-induced vomiting, alopecia, skin and systemic side effect and pain, changes in their work environment and alteration of femininity, sexuality and attractiveness, financial problems, importance of menopausal symptoms such as hot flashes burden and presence of lymphoedema ${ }^{8}$ are factors that can precipitate psychological distress even years after diagnosis and treatment, 7,9-10 which will affect quality of life. Psychological discomfort among breast cancer patients are related with depression and depressive disorders, anxiety, anger and low self-esteem and low emotional support.11 Depression is the most common psychological disorder affecting breast cancer. Risk factors of depression might impair the quality of life such as fatigue, past history or recent episode of depression after the onset of breast cancer, cognitive attitudes of helplessness or hopelessness and resignation. ${ }^{12,13}$ Quality of life indicates a subjective and multidimensional concept commonly composed of physical, social, emotional, mental and functional health domains. ${ }^{14}$ In other words, quality of life characterises the conditions of physical, psychological and social well-being. ${ }^{15}$ Prevalence of mood disorders in breast cancer, the spectrum of psychiatric disorders and psychological distress in cancer has been assessed for many years and several studies.16-19 It is roughly estimated that nearly $50 \%$ of cancer patients suffer from one or the other psychiatric disorders.

\section{Objectives}

To assess the quality of life of paclitaxel-based dose dense and conventional neoadjuvant chemotherapy in locally advanced female breast cancer patients.

\section{MATERIALS AND METHODS \\ Study Design \\ Type of Study \\ Observational study design.}

\section{Study Population}

Locally advanced female breast cancer patients selected from Department of Oncology, Medical College, Thiruvananthapuram, between January 2011 and November 2012.

\section{Study Period}

10 weeks (During neoadjuvant chemotherapy).

\section{Inclusion Criteria}

1. Patients should have locally advanced female breast cancer.

2. Breast cancer should be biopsy proven.

3. Patients age between 25 and 65 .

4. Patients should have normal Haemoglobin (More than or

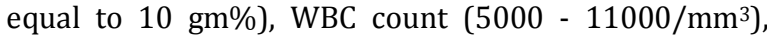
platelet count $\left(70000-300000 / \mathrm{mm}^{3}\right)$, liver function test and renal function test.

\section{Exclusion Criteria}

1. Any previous cancer treatment.

2. Uncompensated congestive heart failure, renal failure and diabetes mellitus.

3. Supraclavicular lymph nodes and distant metastasis from breast cancer.

4. Ulcerative and inflammatory breast cancer.

5. Poor performance status.

6. Pregnancy.

\section{Sample Size}

Sample size was calculated for convenience.

\section{Study Procedure}

In our Department, locally advanced female breast cancer patients receiving different types of paclitaxel containing neoadjuvant chemotherapy. In one pilot study, it had been observed that weekly Paclitaxel improves pathologic complete remission in locally advanced female breast cancer patients when compared with Paclitaxel once every 3 weeks, but quality of life is better in patients receiving 3 weekly Paclitaxel. In our study, we selected the locally advanced female breast cancer patients receiving dose dense (weekly) and conventional (three weekly) were selected and compared their quality of life during paclitaxel based neoadjuvant chemotherapy. This study was approved by the Ethics Committee. The aim of the research and interview method was explained to the participants. All patients signed an informed consent. Patients who refused to enter the study were also excluded.

Fifty patients treated with paclitaxel $200 \mathrm{mg} / \mathrm{m}^{2}$ and doxorubicin $50 \mathrm{mg} / \mathrm{m}^{2}$ (4 course) every three weekly and other fifty treated with paclitaxel $80 \mathrm{mg} / \mathrm{m}^{2}$ weekly (10 course) along with doxorubicin $50 \mathrm{mg} / \mathrm{m}^{2}$ (4 course) every three weekly. Patients received dexamethasone $8 \mathrm{mg}$, diphenhydramine $50 \mathrm{mg}$ and ranitidine $50 \mathrm{mg}$ intravenously as paclitaxel premedication at 12 hours and 30 minutes before starting chemotherapy. Antiemetic- ondansetron $8 \mathrm{mg}$ given intravenously in both arms before starting chemotherapy followed by tablet ondansetron $8 \mathrm{mg}$ and tablet ranitidine $150 \mathrm{mg}$ given morning and evening for 3 days. In all patients, neoadjuvant chemotherapy completed at the end of 9th week. Prophylactic growth factor support was given after 72 hours of paclitaxel in all patients.

\section{Total Cumulative Dose Weekly Patients-}

Paclitaxel $-80 \mathrm{mg} / \mathrm{m}^{2} \times 10$ course weekly $=800 \mathrm{mg} / \mathrm{m}^{2}$

Doxorubicin- $50 \mathrm{mg} / \mathrm{m}^{2} \times 4$ course three weekly $=200$ $\mathrm{mg} / \mathrm{m}^{2}$ 
Total Cumulative Dose Three Weekly Patients-

Paclitaxel- $200 \mathrm{mg} / \mathrm{m}^{2} \times 4$ course three weekly $=800$ $\mathrm{mg} / \mathrm{m}^{2}$

Doxorubicin $-50 \mathrm{mg} / \mathrm{m}^{2} \times 4$ course three weekly $=200$ $\mathrm{mg} / \mathrm{m}^{2}$

Cumulative dose $800 \mathrm{mg} / \mathrm{m}^{2}$ Paclitaxel and $200 \mathrm{mg} / \mathrm{m}^{2}$ Doxorubicin in both arms.

\section{Quality of Life- Assessment}

Chemotherapy induced toxicities, common and serious clinical problems that is adversely affecting the quality of life of patients evaluated weekly by clinical examination and interview (Started after the first week of chemotherapy and completed at the end of tenth week) and compared average mean scores on different domains of quality of life between weekly arm and three weekly arm by using FACT-B, Karnofsky Performance Status and Hamilton Depression scale.

FACT-B (Functional Assessment of Cancer Therapy of Breast). FACT-B comprised of subscales assessing Physical Well-Being (PWB), Social/ Family Well-Being (SFWB), Emotional Well-Being (EWB), Functional Well-Being (FWB) and Additional concerns (short of breath, dressing, swollen or tenderness of arms, sexually, hair loss, effect of stress, change in weight, pain, chance of spread to family members etc.) and FACT-Taxane (Functional Assessment of Cancer TherapyTaxane). FACT-Taxane is a self-report instrument that was developed to measure the health related quality of life of patients receiving taxane containing chemotherapy.

Performance status of patients assessed by using Karnofsky Performance Status. Patients were clinically examined and interviewed regarding their ability do daily activities and performance. The scoring was done weekly. 1000 assessments were done in both groups (500 in each group).

\section{Hamilton Rating Scale for Depression}

Hamilton rating scale for depression is a multiple-choice questionnaire, that is clinically used to rate the severity of a patient's major depression. ${ }^{20}$ The question which is designed for adult patient and is in the public domain rate the severity of symptoms observed for adult patient and is in the public domain rate the severity of symptoms observed in depression such as low mood, insomnia, agitation, anxiety and weight loos. Although, the HAM-D form lists 21 items, the scoring is based on the first 17 . It generally takes $15-20$ minutes to complete the interview and score the results. Eight items are scored on a 5-point scale ranging from $0=$ not present to $4=$ severe. Nine are scores from 0 - 2.

\section{Sum the Score-}

$0-7=$ Normal.

8-13 = Mild Depression.

14-18 = Moderate Depression

19-22= Severe Depression

$\geq 22$ = Very Severe Depression.

All statistical calculations were performed using the SPSS 17.0 statistical software. Quantitative variables were expressed as mean and standard deviation. Qualitative variables were expressed as frequency and percentage. Comparison of quantitative variables between two groups were analysed by unpaired t-test and that of qualitative variables were analysed by Chi-square test. A p-value $<.05$ was considered as statistically significant.

Patients underwent modified radical mastectomy and axillary clearance after the $4^{\text {th }}$ week of neoadjuvant chemotherapy. Adjuvant chemotherapy (FAC- fluorouracil $500 \mathrm{mg} / \mathrm{m}^{2}$, doxorubicin $50 \mathrm{mg} / \mathrm{m}^{2}$, cyclophosphamide 500 $\mathrm{mg} / \mathrm{m}^{2}$ four courses) was given after the two weeks of surgery and external beam radiotherapy dose of 50 Gy in 25 fractions, 5 days/ week total of 5 weeks using co-radioactive isotope (average energy of $1.25 \mathrm{MeV}$ ) with medical and lateral tangential beams and supraclavicular on field. Adjuvant hormone therapy (Premenopausal patientsTamoxifen, Post-Menopausal patients- Letrozole/ Anastrozole) given after radiation those who have receptor status positive.

\section{RESULTS}

\begin{tabular}{|c|c|c|c|c|c|c|c|}
\hline \multirow{3}{*}{\begin{tabular}{|c|} 
Cha \\
Racteris- \\
tics
\end{tabular}} & \multicolumn{4}{|c|}{ Category } & \multirow{3}{*}{$\begin{array}{c}\text { Total } \\
\text { No. } \\
\end{array}$} & \multirow{2}{*}{$\begin{array}{c}X^{2} \\
(d f=2)\end{array}$} & \multirow{2}{*}{$\mathbf{P}$} \\
\hline & \multicolumn{2}{|c|}{3 Weekly } & \multicolumn{2}{|c|}{ Weekly } & & & \\
\hline & No. & $\%$ & No. & $\%$ & & \multirow{5}{*}{0.223} & \multirow{5}{*}{0.895} \\
\hline \multicolumn{6}{|c|}{ Stage } & & \\
\hline $3 a$ & 28 & 56 & 30 & 60 & 58 & & \\
\hline $3 b$ & 14 & 28 & 12 & 24 & 26 & & \\
\hline $3 c$ & 8 & 16 & 8 & 16 & 16 & & \\
\hline \multicolumn{6}{|c|}{ Age } & \multirow{3}{*}{0.041} & \multirow{3}{*}{0.840} \\
\hline$\leq 50$ years & 28 & 56 & 29 & 58 & 57 & & \\
\hline$\geq 50$ years & 22 & 44 & 21 & 42 & 43 & & \\
\hline \multicolumn{6}{|c|}{ Age of Menarche } & \multirow{4}{*}{3.195} & \multirow{4}{*}{0.202} \\
\hline $\begin{array}{l}10-13 \\
\text { years }\end{array}$ & 12 & 24 & 10 & 20 & 22 & & \\
\hline $\begin{array}{l}14-16 \\
\text { years }\end{array}$ & 38 & 76 & 37 & 74 & 75 & & \\
\hline$>16$ years & 0 & 0 & 3 & 6 & 3 & & \\
\hline \multicolumn{6}{|c|}{ Marital Status } & \multirow{3}{*}{1.042} & \multirow{3}{*}{0.307} \\
\hline Married & 49 & 98 & 47 & 94 & 96 & & \\
\hline Unmarried & 1 & 2 & 3 & 6 & 4 & & \\
\hline \multicolumn{6}{|c|}{ Parity } & \multirow{5}{*}{2.347} & \multirow{5}{*}{0.504} \\
\hline Null parity & 1 & 2 & 3 & 6 & 4 & & \\
\hline 1 child & 5 & 10 & 7 & 14 & 12 & & \\
\hline 2 children & 38 & 76 & 37 & 74 & 75 & & \\
\hline 3 children & 6 & 12 & 3 & 6 & 9 & & \\
\hline \multicolumn{6}{|c|}{ Menopause Status } & \multirow{3}{*}{0.208} & \multirow{3}{*}{0.648} \\
\hline $\begin{array}{c}\text { Pre- } \\
\text { menopause }\end{array}$ & 12 & 24 & 14 & 28 & 26 & & \\
\hline $\begin{array}{c}\text { Post- } \\
\text { menopause }\end{array}$ & 38 & 76 & 36 & 72 & 74 & & \\
\hline
\end{tabular}

\begin{tabular}{|c|c|c|}
\hline Karnofsky Performance Status & 3 Weekly & Weekly \\
\hline 70 & $0.5 \%$ & $1 \%$ \\
\hline 80 & $7 \%$ & $17 \%$ \\
\hline 90 & $92 \%$ & $80 \%$ \\
\hline 100 & $0.5 \%$ & $2 \%$ \\
\hline \multicolumn{2}{|c|}{ Table 2. Karnofsky Performance Status } \\
\hline
\end{tabular}

Table shows that $80 \%$ of assessments in patients on weekly group showed a performance scale of 90 as compared to $92 \%$ of those on 3 weekly group. A decline of the 
performance status to 80 was $17 \%$ in weekly group and $7 \%$ in three weekly group.

\begin{tabular}{|c|c|c|c|c|c|c|}
\hline \multirow{2}{*}{$\begin{array}{c}\text { Hamilton } \\
\text { Depression } \\
\text { Score }\end{array}$} & \multicolumn{4}{|c|}{ Category } & \multicolumn{2}{|c|}{ Total } \\
\cline { 2 - 7 } & $\mathbf{3}$ Weekly & \multicolumn{2}{c|}{ Weekly } & \multicolumn{2}{c|}{} \\
\hline Mild 8 - 13 & 23 & 46 & 15 & 30 & 38 & 38 \\
\hline $\begin{array}{c}\text { Moderate } \\
14-18\end{array}$ & 25 & 50 & 31 & 62 & 56 & 56 \\
\hline $\begin{array}{c}\text { Severe } \\
19-22\end{array}$ & 2 & 4 & 4 & 8 & 6 & 6 \\
\hline Total & $\mathbf{5 0}$ & $\mathbf{1 0 0}$ & $\mathbf{5 0}$ & $\mathbf{1 0 0}$ & $\mathbf{1 0 0}$ & $\mathbf{1 0 0}$ \\
\hline
\end{tabular}

\begin{tabular}{|c|c|c|c|c|c|c|}
\hline $\begin{array}{c}\text { Hamilton } \\
\text { Depression } \\
\text { Score }\end{array}$ & Category & No. & Mean & $\begin{array}{l}\text { Standard } \\
\text { Deviation }\end{array}$ & T & P \\
\cline { 2 - 7 } & Weekly & 50 & 14.82 & 2.760 & 1.562 & 0.122 \\
\cline { 2 - 7 } & 3 Weekly & 50 & 14.04 & 2.204 & & \\
\hline
\end{tabular}

\begin{tabular}{|c|c|c|}
\hline & 3 Weekly & Weekly \\
\hline Minimum & 10 & 9 \\
\hline Q1 & 12.5 & 13 \\
\hline Medium & 14 & 15 \\
\hline Q3 & 16 & 17 \\
\hline Maximum & 19 & 20 \\
\hline P & 0.079 & \\
\hline
\end{tabular}

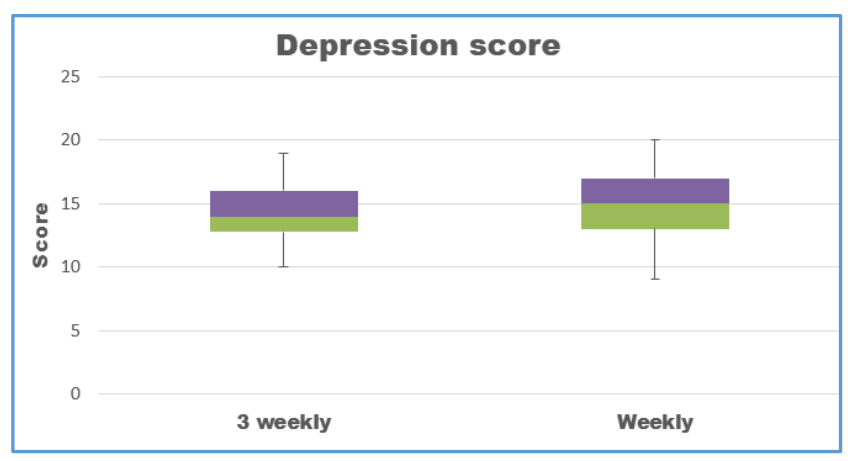

Hamilton Rating Scale for Depression- Box Plot Diagram

Box plot diagram describing the depression score of weekly and 3 weekly chemotherapy given patients. Lower and upper end of the whisker of the box plot represents the minimum and maximum score in each category respectively. Lower and upper border of the box represents first quartile (25 $5^{\text {th }}$ percentile) and third quartile ( $75^{\text {th }}$ percentile) of the depression score respectively. Line of separation of the twocoloured rectangles is the median score. Means value in weekly group is 14.82 with minimum value 9 and maximum value 20 . Means value in three weekly group is 14.04 with minimum value of 10 and maximum value of 19 .

\begin{tabular}{|c|c|c|c|c|c|c|}
\hline Qualities & & No. & Mean & $\begin{array}{r}\text { Standard } \\
\text { Deviation }\end{array}$ & T & P \\
\hline \multirow{2}{*}{ Physical } & weekly & 50 & 10.5 & 1.8 & \multirow{2}{*}{0.845} & 0.400 \\
\cline { 2 - 7 } & 3 weekly & 50 & 10.3 & 1.3 & & \\
\hline \multirow{2}{*}{$\begin{array}{c}\text { Social/ } \\
\text { Family }\end{array}$} & weekly & 50 & 15.4 & 2.5 & \multirow{2}{*}{2.749} & 0.007 \\
\cline { 2 - 7 } & 3 weekly & 50 & 14.3 & 1.5 & & \\
\hline \multirow{2}{*}{ Functional } & weekly & 50 & 9.1 & 1.6 & \multirow{2}{*}{3.263} & 0.002 \\
\cline { 2 - 7 } & 3 weekly & 50 & 10.3 & 2.1 & & \\
\hline
\end{tabular}

\begin{tabular}{|c|c|c|c|c|c|c|}
\hline \multirow{2}{*}{ Emotional } & weekly & 50 & 11.8 & 2.7 & \multirow{2}{*}{2.795} & 0.006 \\
\cline { 2 - 6 } & 3 weekly & 50 & 10.6 & 1.5 & & \\
\hline $\begin{array}{c}\text { Additional } \\
\text { Concerns }\end{array}$ & weekly & 50 & 22.92 & 5.2 & \multirow{2}{*}{3.019} & 0.003 \\
\cline { 2 - 7 } & 3 weekly & 50 & 20.34 & 3.06 & & \\
\hline $\begin{array}{c}\text { Taxane } \\
\text { Toxicity }\end{array}$ & weekly & 50 & 35.04 & 8.06 & \multirow{2}{*}{2.719} & 0.008 \\
\cline { 2 - 5 } & 3 weekly & 50 & 31.12 & 5.52 & & \\
\hline
\end{tabular}

Table 4. Comparison of Average Scores on different domains of Quality of Life between Weekly Group and Three Weekly Group

Average physical well-being mean score among the weekly patients was $10.5 \pm 1.8$ and that among the three weekly patients was $10.3 \pm 1.3$. The observed difference in score among the two groups was not statistically significant.

Average social well-being mean score among the weekly patients was $15.4 \pm 2.5$ and that among the three weekly patients was $14.3 \pm 1.5$. The observed difference in score among the two groups was statistically significant $(p=0.007)$.

Average functional well-being mean score among the weekly patients was $9.1 \pm 1.6$ and that among the three weekly patients was $10.3 \pm 2.1$. The observed difference in score among the two groups was statistically significant ( $\mathrm{p}=0.007)$.

Average emotional well-being means score among the weekly patients was $11.8 \pm 2.7$ and that among the three weekly patients was $10.6 \pm 1.5$. The observed difference in score among the two groups was statistically significant $(\mathrm{p}=0.006)$.

Average additional concerns regarding breast chemotherapy means score among the weekly patients was $22.92 \pm 5.2$ and that among the three weekly patients was $20.34 \pm 3.06$. The observed difference in score among the two groups was statistically significant $(\mathrm{p}=0.003)$.

Average taxane toxicity during breast chemotherapy, mean score among the weekly patients was $35.04 \pm 8.56$ and that among the three weekly chemotherapy patients was $31.12 \pm 5.52$. The observed difference in score among the two groups was statistically significant $(p=0.008)$.

\section{DISCUSSION}

Breast cancer is the most common type of tumour and the leading cause of cancer deaths in women. There are several therapeutic approaches to treat these patients. Each has its own particular effects and complications, which can determine a patient's survival and quality of life.21 Neoadjuvant chemotherapy has been used to treat women with locally advanced breast cancer in an attempt to render the tumour operable.22,23 Anthracycline and taxane-based regimens are the backbones of most neoadjuvant chemotherapy protocols for breast cancer. ${ }^{24} \mathrm{~A}$ study by Green et al demonstrated weekly administration of paclitaxel is associated with an improved response rate and time to tumour progression when compared to the standard threeweekly treatment. 25

Hürny et al have reported a significant relationship between chemotherapy and the quality of life of women with breast cancer. ${ }^{26}$ Stein et al showed that women with breast cancer treated with radiotherapy and chemotherapy suffered from poor sleep quality and had lower quality of life. 27 Hatam et al observed a vast increase in side effects such as constipation, nausea, stomatitis, fatigue and alopecia during chemotherapy. ${ }^{21}$ Mohadesi et al have concluded that fatigue was the most common complication caused by treatment in patients with breast cancer. ${ }^{28}$ 
Abdel Halim and M El Ashri conducted a study in metastatic breast cancer. ${ }^{29}$ That study showed that after adjuvant anthracycline treatment, weekly paclitaxel 80 $\mathrm{mg} / \mathrm{m}^{2}$ (And every 4 weekly paraplatin AUC5) seems less toxic and more efficient compared with 3 weekly paclitaxel $175 \mathrm{mg} / \mathrm{m}^{2}$ (And paraplatin AUC5 every 3 weeks).

Comparison of the mean quality of life scores both arms were done. Chemotherapy-induced toxicities are common and serious clinical problems that adversely impact both the quality of life and the ability of patients to continue treatment for their cancer. This study has shown that at the end of neoadjuvant chemotherapy, quality of life in both groups deteriorated as a result of the side effects and reveals the difference from the initial results. ${ }^{30}$

Weekly patients had more physical problem than three weekly due to chemotherapy-induced toxicities (Haematological, neurological-paraesthesias), lack of energy, body pain, frequent hospital visit etc., but not statistically significant. Physical well-being increases as total score decrease.

Weekly patients have significant more social/ family wellbeing than three weekly patients. Patients are satisfied with family communication about their illness and get support from their friends. Social well-being increases as total score increases.

Weekly patients have significantly less functional wellbeing than the three weekly patients, mainly due to physical problems. Functional well-being like able to work at home, enjoy life and sleeping are better in three weekly patients. Functional well-being increases as total score increases. Based on Karnofsky performance status, three weekly patients had better performance status than weekly patients. Weekly patients have significantly less emotional well-being than the three weekly patients due to depression, feeling of sad, fear of death and recurrence. Emotional well-being increases as total score decreases. Hamilton Rating Scale for Depression and Box plot diagram describing the depression score of weekly and 3 weekly patients. Both arm patients had depression after diagnosis. Moderate and severe depression is more in weekly arm than three weekly arm. There is no statistically significant difference between two arms. Weekly patients have significantly more additional chemotherapy related problems (Short of breath, dressing, swollen or tenderness of arms, sexually, hair loss, effect of stress, change in weight, pain and chance of spread to family members etc.) than three weekly patients. Additional chemotherapy related problems increase as total score increases.

Weekly patients have significantly more Taxane toxicity (Numbness of hands and feet (peripheral neuropathy), joint pain or muscle cramps etc.) than three weekly patients.

\section{CONCLUSION}

Stress, pain and fatigue can severely diminish quality of life during and after cancer treatment. This study show that the quality of life was better in three weekly neoadjuvant chemotherapy patients due to significantly more functional and emotional well-being, less chemotherapy related toxicity and physical problem. Promote physical therapy, accepting illness, maintain regular sleep, manage hair loss by wig, coping strategies or addressing spiritual concerns, emotional support from family and friends, reading books, using laptop and music player and deep breathing or guided imagery to reduce stress. A team of doctors, nurses and other health care professionals working together with the patient, their family and caregivers to understand the patient's goals, explain treatment options and provide good general hygiene, comfortable clothes, hydration and management of toxicity to increase quality of life before and after chemotherapy.

\section{REFERENCES}

[1] DeVita VT, Lawrence TS, Rosenberg SA. Devita, Hellman \& Rosenberg's cancer: principles \& practice of oncology. $8^{\text {th }}$ edn. Philadelphia: Wolters Kluwer /Lippincott Williams \& Wilkins 2008.

[2] Cristofanilli M, Gonzalez-Angulo AM, Buzdar AU, et al. Paclitaxel improves the prognosis in estrogen receptor negative inflammatory breast cancer: the M.D Anderson Cancer Center experience. Clin Breast Cancer 2004;4(6):415-9.

[3] McGurie SE, Gonzalez-Angulo AM, Huang EH, et al. Post mastectomy radiation improves the outcome of patients with locally advanced breast cancer who achieve a pathologic complete response to neoadjuvant chemotherapy. Int J Radiat Oncol Biol Phys 2007;68(4):1004-9.

[4] Sikov WM Akerley W, Cummings F, et al. Weekly highdose paclitaxel in metastatic and locally advanced breast cancer: a preliminary report. Semin Oncol 1997;24(5 Suppl 17):S17-87-S17-90.

[5] Chu E, DeVita VT. Physicians' cancer chemotherapy drug manual 2012. $12^{\text {th }}$ edn. Jones \& Bartlett Learning 2012.

[6] Del Gaudio D, Menonna-Quinn D. Chemotherapy. Potential occupational hazards. Am J Nurs 1998;98(11):59-65.

[7] CDC Staff. Understanding Depression - Yours Theirs. CDC gov.01 Apr-2002. Centers for Disease Control and Prevention. 23 Apr 2008.

[8] Grabsch B, Clarke DM, Love A, et al. Psychological morbidity and quality of life in women with advanced breast cancer: a cross-sectional survey. Palliat Support Care 2006;4(1):47-56.

[9] Meyerowitz BE. Psychosocial correlate of breast cancer and its treatments. Psychol Bull 1980;87(1):108-31.

[10] Spiegel D. Psychosocial aspects of breast cancer treatment. Semin Oncol 1997;24(1 Suppl 1):S1.36S1.47.

[11] Baucom DH, Porter LS, Kirby JS, et al. Psychosocial issues confronting young women with breast cancer. Breast Dis 2006;23(1):103-13.

[12] Okamura M, Yamawaki S, Akechi T, et al. Psychiatric disorders following first breast cancer recurrence: prevalence associated factors and relationship to quality of life. Jpn J Clin Oncol 2005;35(6):302-9.

[13] Kissane DW Grabsch B, Love A, et al. Psychiatric disorder in women with early stage and advance breast cancer: a comparative analysis. Aust NZ J Psychiarty 2004;38(5):320-6.

[14] Flaskerud JH, Carter PA, Lee P. Distressing emotions in female caregivers of people with AIDS, age-related dementias, and advanced-stage cancers. Perspect Psychiatr Care 2000;36(4):121-30. 
[15] Gordon LG, Battistutta D, Scuffham P, et al. The impact of rehabilitation support services on health-related quality of life for women with breast cancer. Breast Cancer Res Treat 2005;93(3):217-26.

[16] Hegel MT, Moore CP, Collins ED, et al. Distress, psychiatric, syndromes, and impairment of function in women with newly diagnosed breast cancer. Cancer 2006;107(12):2924-31.

[17] Derogatis LR, Morrow GR, Fetting J, et al. The prevalence of psychiatric disorders among cancer patients. JAMA 1983;249(6):751-7.

[18] Harter M, Retuer K, Aschenbrenner A, et al. Psychiatric disorders and associated factors in cancer: results of an interview study with patient in inpatient, rehabilitation and out-patients treatment. Eur J Cancer 2001;37(11):1385-93.

[19] Zabora J, BrintzenhofeSzoc K, Curbow B, et al. The prevalence of psychological distress by cancer site. Psychooncology 2001;10(1):19-28.

[20] Cella DF, Tulsky DS, Gray G, et al. The functional assessment of cancer therapy scale: development and validation of the general measure. J Clin Oncol 1993;11(3):570-9.

[21] Hatam N, Ahmadloo N, Daliri AAK, et al. Quality of life and toxicity in breast cancer patients using adjuvant TAC (docetaxel, doxorubicin, cyclophosphamide), in comparison with FAC (doxorubicin, cyclophosphamide, 5-fluorouracil). Arch Gynecol Obstet 2011;284(1):215-20.

[22] Bear HD. Indications for neoadjuvant chemotherapy for breast cancer. Semin Oncol 1998;25(2 Suppl 3):312.
[23] Hortobagyi GN. Comprehensive management of locally advanced breast cancer. Cancer 1990;66(6 Suppl):1387-91.

[24] Carlson RW, Anderson BO, Burstein HJ, et al. Invasive breast cancer. J Natl Compr Canc Netw 2007;5(3):246312.

[25] Green MC, Buzdar AU, Smith T, et al. Weekly paclitaxel improves pathologic complete remission in operable breast cancer when compared with paclitaxel once every 3 weeks. J Clin Oncol 2005;23(25):5983-92.

[26] Hurny C, Bernhard J, Coates AS, et al. Impact of adjuvant therapy on quality of life in women with node-positive operable breast cancer. International Breast Cancer Study Group. Lancet 1996;347(9011):1279-84.

[27] Stein KD, Jacobsen PB, Hann DM, et al. Impact of hot flashes on quality of life among postmenopausal women being treated for breast cancer. J Pain Symptom Manage 2000;19(6):436-45.

[28] Mohadesi HAH, Hasanzadeh G, Yegansangi M. The Survey of quality of life in breast cancer under chemotherapy in orumie. [Article in Persian] IJBD 2013;5(4):35-43.

[29] Abdel Halim II, El Ashri M, El Sadda W. Weekly paclitaxel versus standard 3-week schedule in patients with metastatic breast cancer. Journal of Clinical Oncology 2011;29(15 Suppl):627-7.

[30] Rezapour A, Javan-Noughabi J, Faramarzi A, et al. Quality of life in breast cancer patients using neoadjuvant AC (Doxorubicin and Cyclophosphamide) in comparison with PG (Paclitaxel and Gemcitabine) therapy. MEJC 2018;9(1):41-7. 